\title{
Design Improvements in a 30,000 kcal/h Air Furnace, Assisted by CFD and Infrared Thermography
}

\author{
D. Tziourtzioumis and A. Stamatelos*
}

\author{
Laboratory of Thermodynamics and Thermal Engines, Department of Mechanical Engineering, University of Thessaly, \\ GR- 38334 Volos, Greece
}

\begin{abstract}
The design of low-end, oil or natural gas-fired air furnaces is currently carried out using traditional methodologies. On the other hand, the use of modern computational tools can be promising also in this category of equipment, especially if assisted by modern, non-intrusive experimental techniques of low operational cost. In this paper, we report on the use of commercial computational fluid dynamics (CFD) software, assisted by infrared thermography, to predict and improve the flow and heat transfer in a $30,000 \mathrm{kcal} / \mathrm{h}$ air furnace. The infrared thermography was employed in the determination of temperature boundary conditions in the heat exchanger surfaces. The 3D flow and heat transfer in the main control volume of the air furnace, at steady state (nominal operation point) is computed and presented by means of 3D streamlines and velocity and temperature fields at characteristic cross sections. The numerical results were checked by means of energy balances in the inlet and outlet sections of the control volume enclosing the heated air stream. In this way, the air furnace efficiency can be computationally predicted. Significant improvements in the traditional design process are demonstrated by means of this procedure. Thus, a promising design methodology for air furnaces, which is assisted by modern computational and experimental tools, can be formulated.
\end{abstract}

\section{INTRODUCTION}

The design of central heating boilers and furnaces was traditionally based on a modular construction using standardized cast-iron parts. In parallel, welded steel sheet boilers have been popular after World War II. This type of boiler allowed a lower cost and more flexible design, at the penalty of a reduced lifetime. Starting from the first energy crisis, the specialized manufacturers started to produce optimized boiler designs depending on the type of fuel (coal, wood or biomass, light diesel, natural gas etc). The design changes aimed at minimization of exhaust gas, radiation, shell and intermittent operation losses [1].

The operation temperature of boilers has been progressively decreasing, taking measures at the same time to avoid condensation of water vapor in their flue gas pipe. Very important improvements have been achieved by means of the so called "condensing boilers and furnaces" (up to $109 \%$ efficiency, if one refers to the lower heating value of the fuel). In parallel with the development of their individual parts (boiler, burner, control equipment), the possibilities of modern microprocessor control are exploited in modern equipment. In the present work, we address the use of modern computational and other tools to the designing optimization of air furnaces (Fig. 1).

Significant efforts for efficiency improvements in this class of equipment are reported starting from the eighties' employing conventional design methodologies [2, 3]. During the last decade, the efforts are focused in improvements of the combustion control system [4], reduction of emissions

*Address correspondence to this author at the Laboratory of Thermodynamics and Thermal Engines, Department of Mechanical Engineering, University of Thessaly, GR- 38334 Volos, Greece; E-mail: stam@uth.gr and increase of efficiency exploiting the condensation of water vapor inside the furnace heat exchangers $[5,6]$.

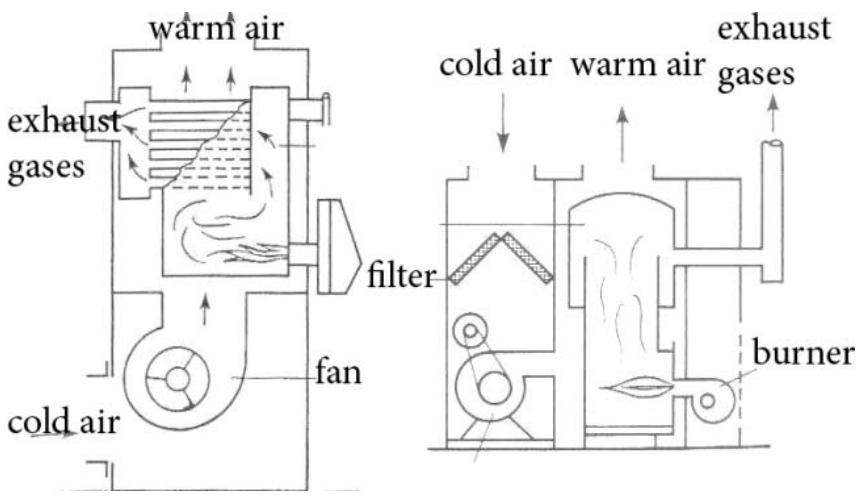

Fig. (1). Design variations of a European (left) and an American (right) - type air furnace.

On the other hand, commercial CFD codes find a continuously increasing application in the design of industrial equipment, following the significant improvements in preprocessing and flexibility in addressing an increasing number of application cases. The applications in industrial boilers have been considerably increasing during the last decade, with the study of power station equipment (hundreds of MW) addressing the highest interest [7-11]. Emphasis is usually in the combustion process, the study of advanced combustion chambers coal combustion in fluidized beds etc

However, the bibliographic research indicates that the possibilities of the above-mentioned computational tools are not yet widely exploited to support the design of smaller units. This is understandable, since the required, significant effort of specialized engineers is not yet affordable by small and medium sized manufacturers that usually produce this 
type of equipment. On the other hand, an important effort continues to be invested internationally in design improvements and patents in this category, although the small boilers continue to be manufactured and designed by the traditional way, addressing the requirements of the pertaining technical standards [12-15] by means of empirical design improvements. This philosophy gives satisfactory results in the case of hydraulic central heating boilers. However, it seems that there exist certain margins for design improvement in the case of air furnaces, where the air-side convection coefficients are generally low and can be considerably improved by improvements in the flow field round the heat exchanger.

The present work was motivated by a small manufacturer [16], active in design improvements of his low end air furnaces (Fig. 2).

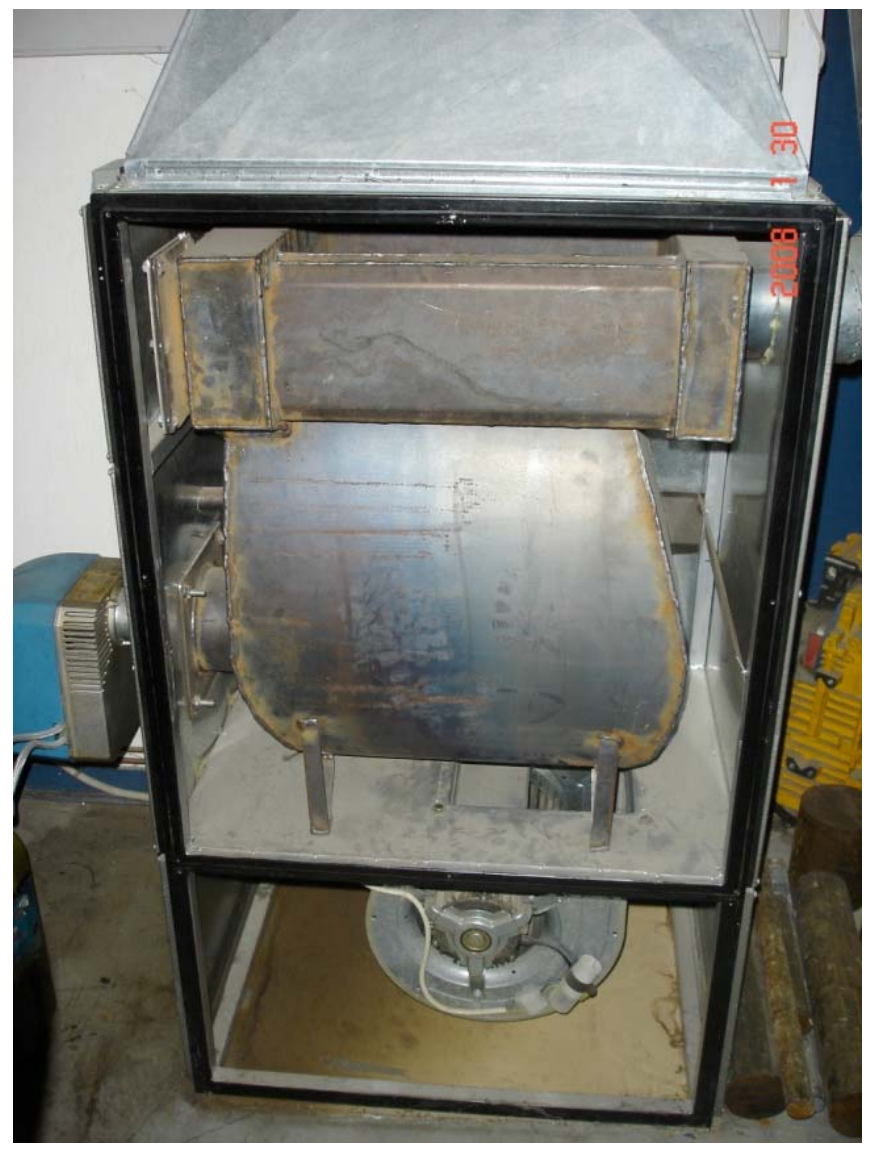

Fig. (2). Exposed heat exchanger surfaces of the 30,000 kcal / h air furnace, after the removal the front cover and the fan inlet grid.

We aim to improve the geometry of the combustion chamber and the heat exchange surfaces between exhaust gas and heated air. For example, it needs to be investigated if it possible to improve efficiency by optimizing the position and dimensions of the inlet section, that guides air from the fan to the heat exchanger, the geometry of the heat exchanger itself etc.

As a rule, the application of CFD must be supported by certain reference measurements, which require the equipment of a prototype with sensors of temperature, pressure, air velocity etc. In the present work, the measurement effort is minimized by exploiting the capabilities of infrared thermography. As it is analyzed in this work, the combination of commercial CFD code [17] with the technique of infrared thermography in the specific design case, led to quite satisfactory results that assisted optimization of the specific line of air furnaces.

\section{SOLUTION METHODOLOGY}

The following methodology was adapted to the specific problem's nature. The methodology is based on the experimentally confirmed assumption that the temperature field in the shell of heat exchanger, is mainly determined by the internal gas flow - temperature field in the combustor - exhaust pipes, and is not considerably influenced by small changes in the external flow field of the heated air. Based on this assumption, we developed the methodology according to the following steps:

- Conducting steady state efficiency and air-to-fuel ratio measurements, at the nominal operation point [20]

- Conducting temperature field measurements with infrared thermography, (infrared camera ThermaCAM S 45)

- $\quad$ Conducting velocity field measurements with a hot wire anemometer (TSI Velocicalc) across the outlet vent

- Conducting velocity measurements with a hot wire anemometer inside the control volume

- $\quad$ Production of a solid model of the heat exchange surfaces, based on existing plans in CAD software (ProEngineer [18]), delivered by the manufacturer [16] The solid model was produced with ANSYS ICEM software.

- Generation of a suitable computational mesh covering over all the control volumes in which the air flow field is developed (software ANSYS ICEM).

- $\quad$ Production of flow and heat transfer boundary conditions (software CFX Pre). A fixed temperature field on the heat exchange surfaces is assumed as a boundary condition. The temperatures are taken by the results of infrared thermography. The mass flowrate of air entering the control volume is estimated based on the fan's characteristics [19] and corrected by an iterative procedure to achieve agreement between experiment and calculation on the efficiency of the air furnace.

- $\quad$ Solution of the 3D flow field equations in steady state condition based on the k- $\varepsilon$-turbulence model (CFX Solver).

- Visualization - presentation of results in the form of streamlines and temperature and velocity contours in characteristic cross-sections (CFX Post).

- $\quad$ Exportation of the results as velocity and temperature fields at the inlet and outlet cross-sections, to enable carrying out mass and energy balances (CFX Post).

- After the above mentioned agreement between experimentally determined and computed efficiency of the air furnace is confirmed the final value is set for air mass flowrate and the computations can be repeated by changing the position and/ or dimensions of 
the air inlet vent etc, to obtain estimates of the expected efficiency improvements.

\section{SOLUTION METHODOLOGY IMPLEMENTATION}

Efficiency and Air-to-Fuel Ratio Measurements

In this phase, measurements of steady state efficiency, temperature of exhaust gases, $\mathrm{A} / \mathrm{F}$ ratio and emissions were conducted at the nominal operation point of the furnace, by use of the measuring device: MRU Vario Plus Industrial [20]. Aim of these measurements was to secure an optimal adjustment of boiler, thus maximizing efficiency with the specific design. Details for this phase are given elsewhere [21]. The maximum efficiency attained was $87.3 \%$, for exhaust gas temperature of $261{ }^{\circ} \mathrm{C}$ and equivalence ratio $\lambda=1.25$.

\section{Measurements with Infrared Thermography}

In this phase, infrared thermography was employed in recording the temperature field at the part of the heat exchanger surface which becomes visible when the front cover is removed (Fig. 2). The experimental setup is shown in Fig. (3).

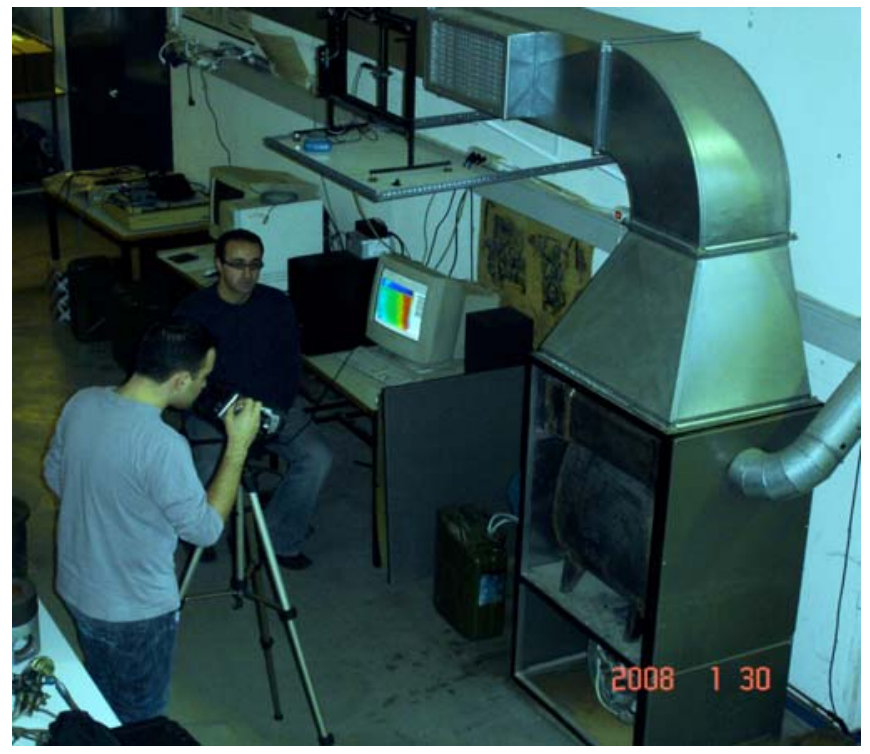

Fig. (3). Measurements with infrared thermography: air furnace in operation, front panel removed. Thermocamera is shown to the left and computer with processing software at the center of the figure.

Fig. (4) shows thermograph with the measured temperature distribution with the air furnace adjusted to its optimal operation point.

Particular attention has been paid in the conduction of thermography measurements at reduced lighting conditions, to minimize any reflection effects on the heat exchanger surfaces. (Nevertheless, some reflections are apparent in Fig. (4), mainly at the right cover of the air furnace). Based on the processing of thermographs taken by various viewpoints, with the aid of the ThermaCAM Researcher software [22], ample information on the temperature field at the heat exchanger surface was collected. The maximum measured temperature was $325{ }^{\circ} \mathrm{C}$. In addition, it was experimentally checked how much the absence of the front panel could possibly affect the temperature field on the surface. To this end, after steady state air furnace's operation at nominal point for
30 minutes, we removed very rapidly (order of $1 \mathrm{~s}$ ) the cover and filmed the temperature field using the infrared camera which was already set up and focused. The analysis of this transient thermograph showed negligible change following the removal of the front panel.

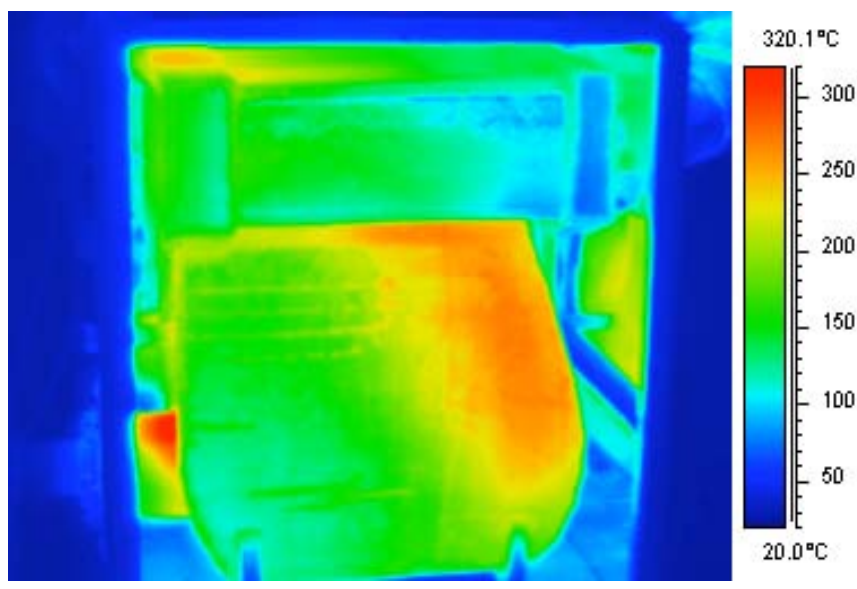

Fig. (4). Temperature distribution at the heat exchanger surfaces at the optimal operation point, resulting from the analysis of the related thermograph. Entry of flamepipe at bottom-left, exhaust outlet at top right. Path of exhaust gas moves from the red colored end of combustion chamber, back to the left side of the exhaust gas tubes.

The constant temperature boundary conditions on the heat exchanger surfaces were selected, based on the processing of the respective thermographs, of the type of Fig. (4).

\section{Measurements at the Vent with Hot Wire Anemometer}

In this phase, measurements with a low cost hot wire anemometer were carried out across the outlet vent, in order to gain information on the air temperature and velocity field at the outlet vent. The experimental procedure followed is described analytically in [21].

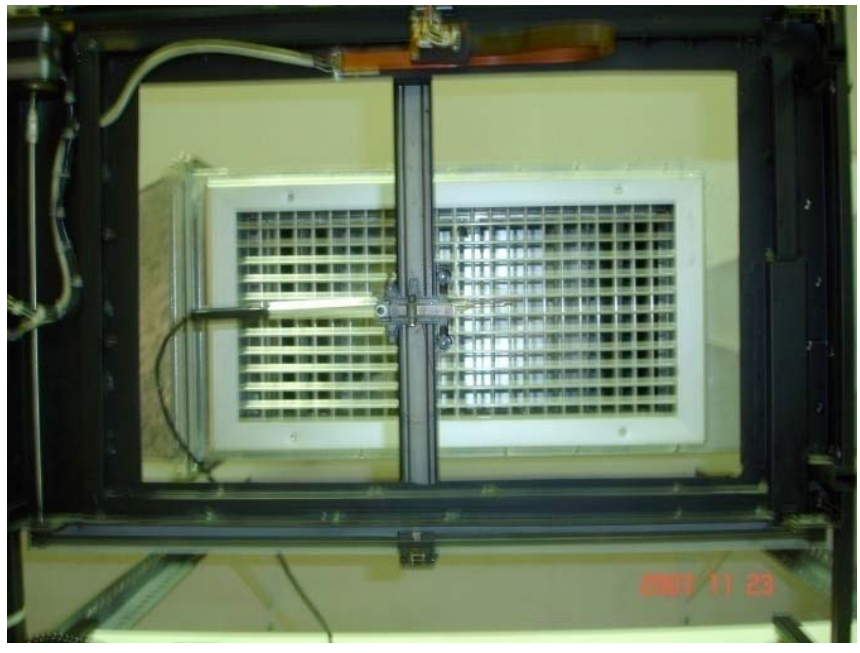

Fig. (5). Scanning device with hot wire probe attached in front of outlet vent for air velocity and temperature measurements.

For the automatic scanning of the vent outlet, a specially designed test rig is employed, which is based on the suitable transformation of a desktop plotter, which, instead of a pen, now moves along preset paths, the probe of a hot wire anemometer (TSI Velocicalc [23]). The scanning device is controlled by HP - GL language. The anemometer exports the 
position and velocity measurements, via serial port communication in Labview software [24]. The probe [23], mounted on the scanning device in front of the air furnace's vent is shown in Fig. (5).

The measurements are shown in Table $\mathbf{1 .}$

Table 1. Measurements in the Exit Air Duct's Vent

\begin{tabular}{|c|c|c|}
\hline $\begin{array}{c}\text { Average } \\
\text { Velocity }[\mathrm{m} / \mathbf{s}]\end{array}$ & $\begin{array}{c}\text { Maximum } \\
\text { Velocity }[\mathbf{m} / \mathbf{s}]\end{array}$ & $\begin{array}{c}\text { Minimum } \\
\text { Velocity }[\mathbf{m} / \mathbf{s}]\end{array}$ \\
\hline \hline 2.20 & 4.65 & 0.20 \\
\hline $\begin{array}{c}\text { Average } \\
\text { Temperature } \\
{\left[{ }^{\circ} \mathrm{C}\right]}\end{array}$ & $\begin{array}{c}\text { Maximum } \\
\text { Temperature }\left[{ }^{\circ} \mathrm{C}\right]\end{array}$ & $\begin{array}{c}\text { Minimum } \\
\text { Temperature }\left[{ }^{\circ} \mathrm{C}\right]\end{array}$ \\
\hline 44.0 & 50.6 & 36.4 \\
\hline
\end{tabular}

The maximum velocity and temperature are observed at the same position.

\section{Solid Modeling and Computational Grid}

The solid model of the heat exchange surfaces was assembled in this phase based on the ProE [18] drawings of the manufacturer [16]. The 3D drawing is imported in ANSYS ICEM software and the solid model is automatically produced. The solid model consists of a number of parts, which are named by the user. The solid model parts are shown in Fig. (6).

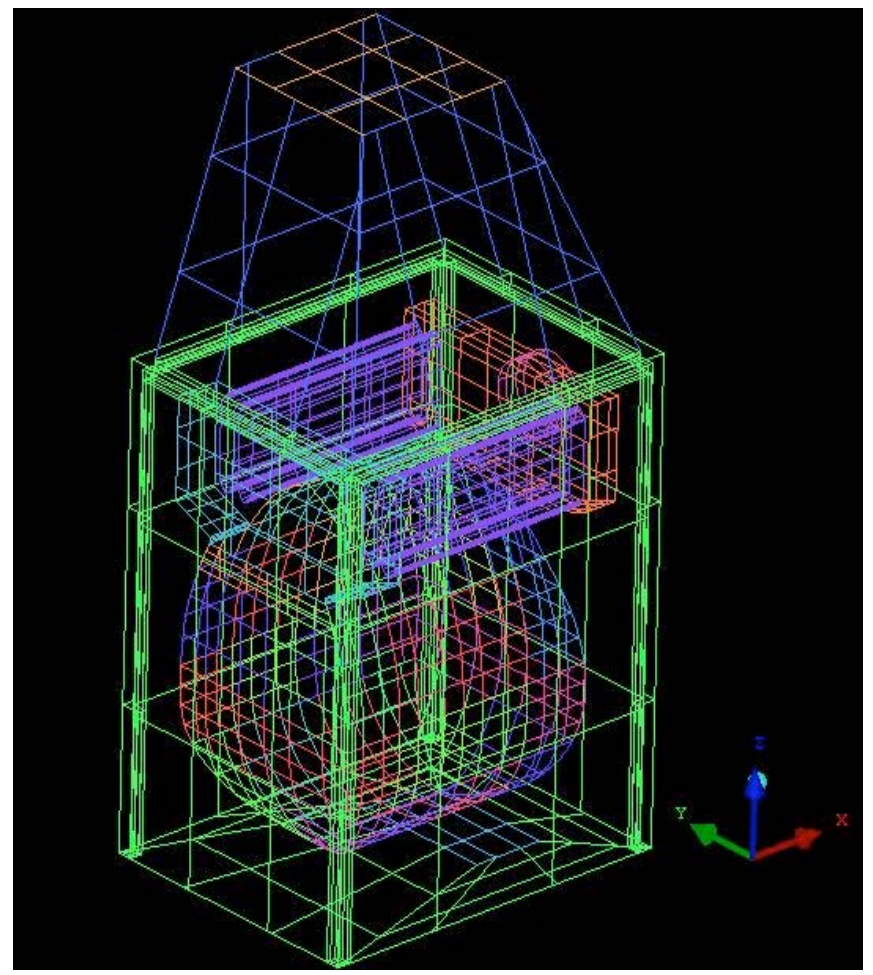

Fig. (6). Solid model of the control volume under study (heat exchange area and outlet plenum).

The next step is the creation of the computational grid. The desirable mesh was created by means of ANSYS ICEM software, as shown in Fig. (7).

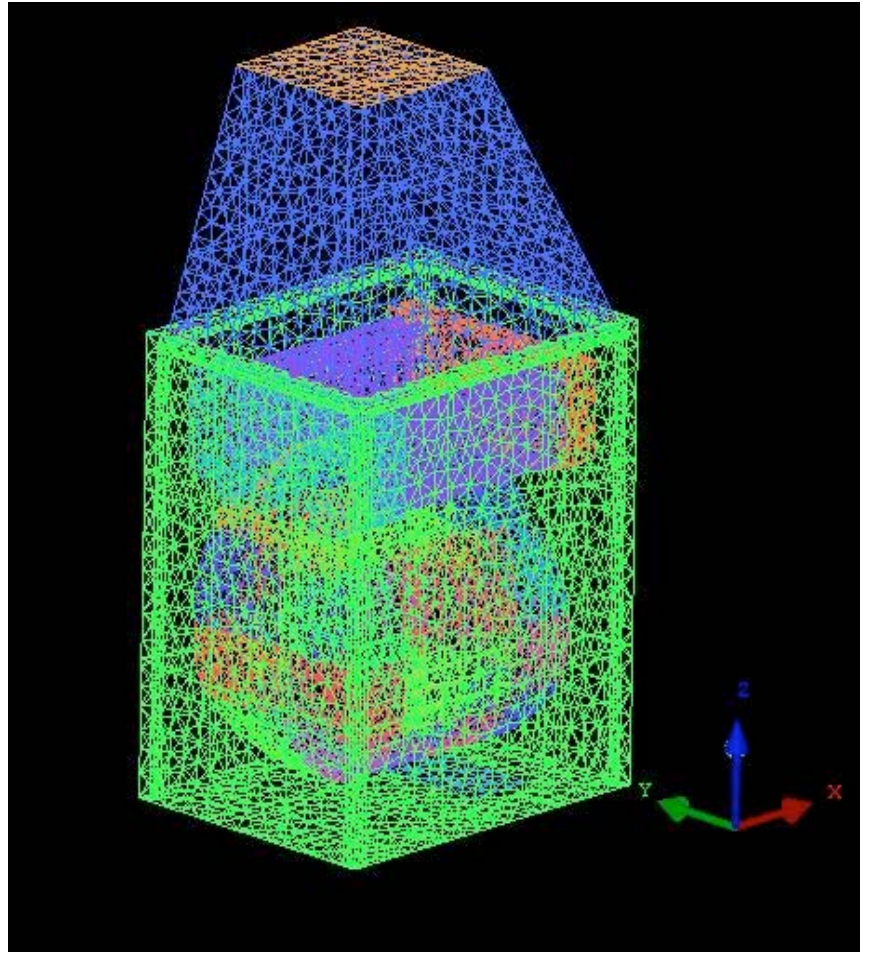

Fig. (7). Computational grid for the control volume.

\section{Determination of Boundary Conditions}

The determination of boundary conditions is realized by means of the CFX - Pre software. The procedure followed is described below: The geometry and the computational mesh are imported and the respective boundary conditions are set in the different parts, one by one:

Inlet: Static Temperature: $\mathrm{T}=20{ }^{\circ} \mathrm{C}$

Mass Flow Rate $=0.8 \mathrm{~kg} / \mathrm{s}$ (is explained below)

Outlet: Gauge Pressure: $\mathrm{P}=60 \mathrm{~Pa}$

Heat exchanger wall: Fixed Temperature: $\mathrm{T}=140^{\circ} \mathrm{C}$

Upstream collector wall: Fixed Temperature: $\mathrm{T}=160{ }^{\circ} \mathrm{C}$

Downstream collector wall: Fixed Temperature: $\mathrm{T}=100{ }^{\circ} \mathrm{C}$

Plenum wall: Heat Transfer Coefficient: $\mathrm{U}=6 \mathrm{~W} / \mathrm{m}^{2} \mathrm{~K}$ (estimated by means of composite resistance)

Outside Temperature: $\mathrm{T}=20{ }^{\circ} \mathrm{C}$

Cover wall: Heat Transfer: Adiabatic

Combustion Chamber: In order to better describe the surface temperature field, the combustion chamber surface was separated in parts which are assumed to have fixed temperature boundary conditions. The average temperature in each part is calculated based on the results of the processing of thermographs [22].

An ideal gas assumption is made for air properties (reference pressure is $1 \mathrm{~atm}$ ).

A fixed mass flowrate inlet boundary condition is set, based on the fan's characteristic curve, based on the procedure reported above. The $250 \mathrm{~W}$ fan is constructed by Tecnifan. Its characteristics were taken from the web site of the manufacturer [19]. 


\section{Solution of the Flow Field Equations}

The solution of the steady state flow field equations is carried out in CFX solver, based on the k - epsilon (k- $\varepsilon$ ) turbulence model ( $5 \%$ turbulence intensity in the inlet boundary condition).

The CFD simulation was performed with an AMD Athlon Dual Core Processor 2.80 GHz with 2.00 GB RAM.

Fig. (7) shows the air furnace geometry and the computational grid which has approximately 100,000 control volumes (tetrahedral).

A maximum of 60 iterations is allowed. Aim was to reduce below 1.0 e-004 all residuals of the continuity, momentum and energy equations.

The CPU time was approximately 20 minutes.

The CFX-Post commercial software was used for the numerical study of the problem. The results, which contain all the essential information on the air flow around the heat exchange surface, can be presented with various ways in any part, surface, of our control volume.

\section{Presentation of Results}

Characteristic figures from the visualization of results, in the form of streamlines and temperature and velocity contours across planes are presented as follows:

Fig. (8) shows the temperature field at the exit of the plenum.
Fig. (9) presents typical streamlines and temperatures of the air flowing around the heat exchanger surfaces.

Fig. (10) shows the velocity field between the heat exchanger surface and the covers.

\section{Mass Balances- Iterative Computation of Mass Flowrate}

CFX Post provides the possibility of exporting text files that contain the values of any thermodynamic variables taking place in the computation. These files are employed in carrying out mass and energy balances. This is a very important part of any study with commercial computational fluid dynamics codes.

Mass balances are computed based on the values of air mass flow rate variation across the inlet and outlet section elements. The cross sections of the respective elements are taken into account for this computation. After following the iterative procedure described above, we found convergence between inlet and outlet mass flowrate in the values of $\dot{m}_{\text {in }}=\dot{m}_{\text {out }}=0.8 \mathrm{~kg} / \mathrm{s}$

\section{Energy Balances - Comparison Between Measurements and Calculations}

The air velocity profile at the entry of the pyramidal outlet plenum (upwards of the heat exchanger see upper part of Fig. (10)), was also measured by the low cost hot wire anemometer, confirming the general form of the computed flow field. Checking of the validity of the CFD computations is

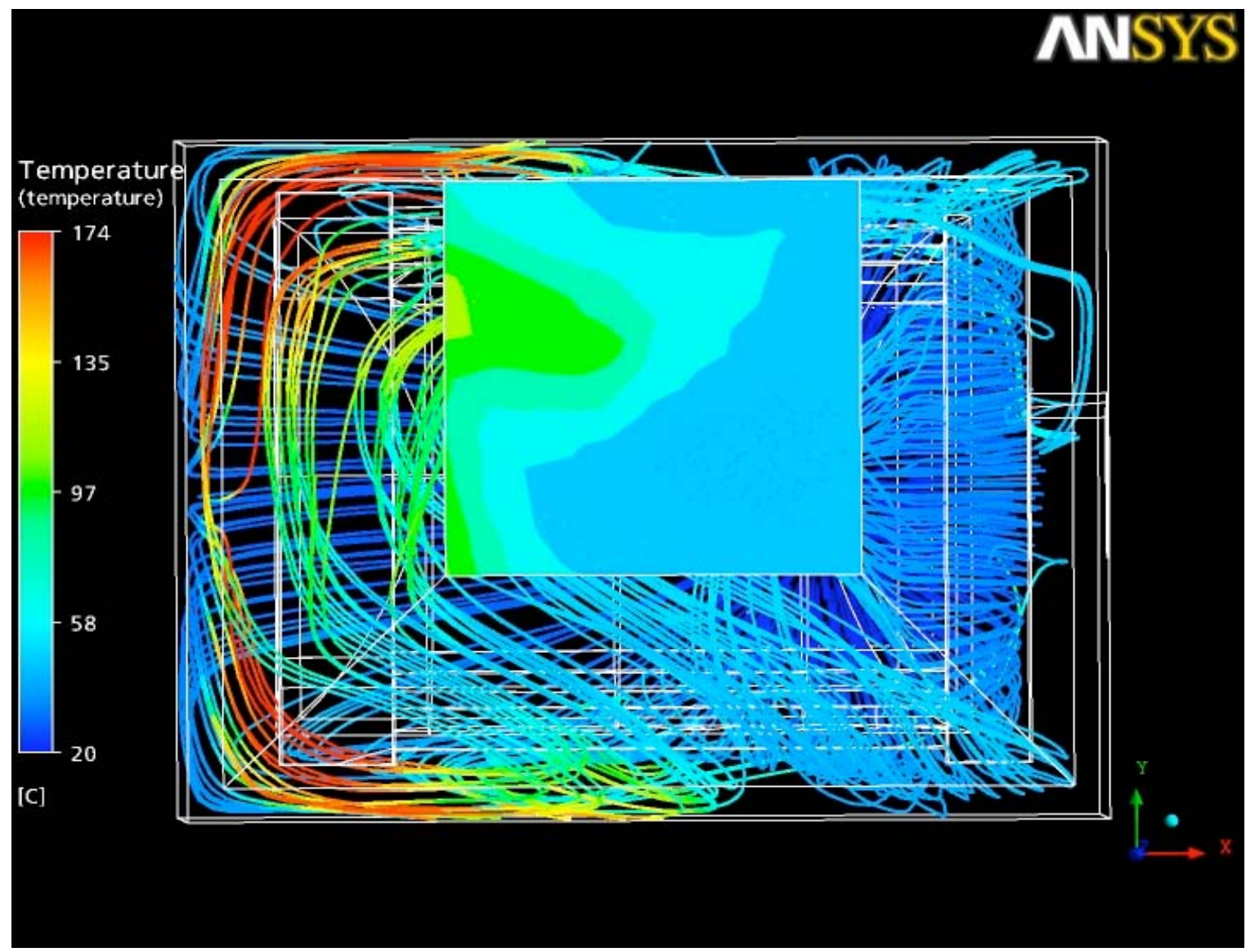

Fig. (8). Computed temperature field at the exit of plenum and at the streamlines inside the control volume. 


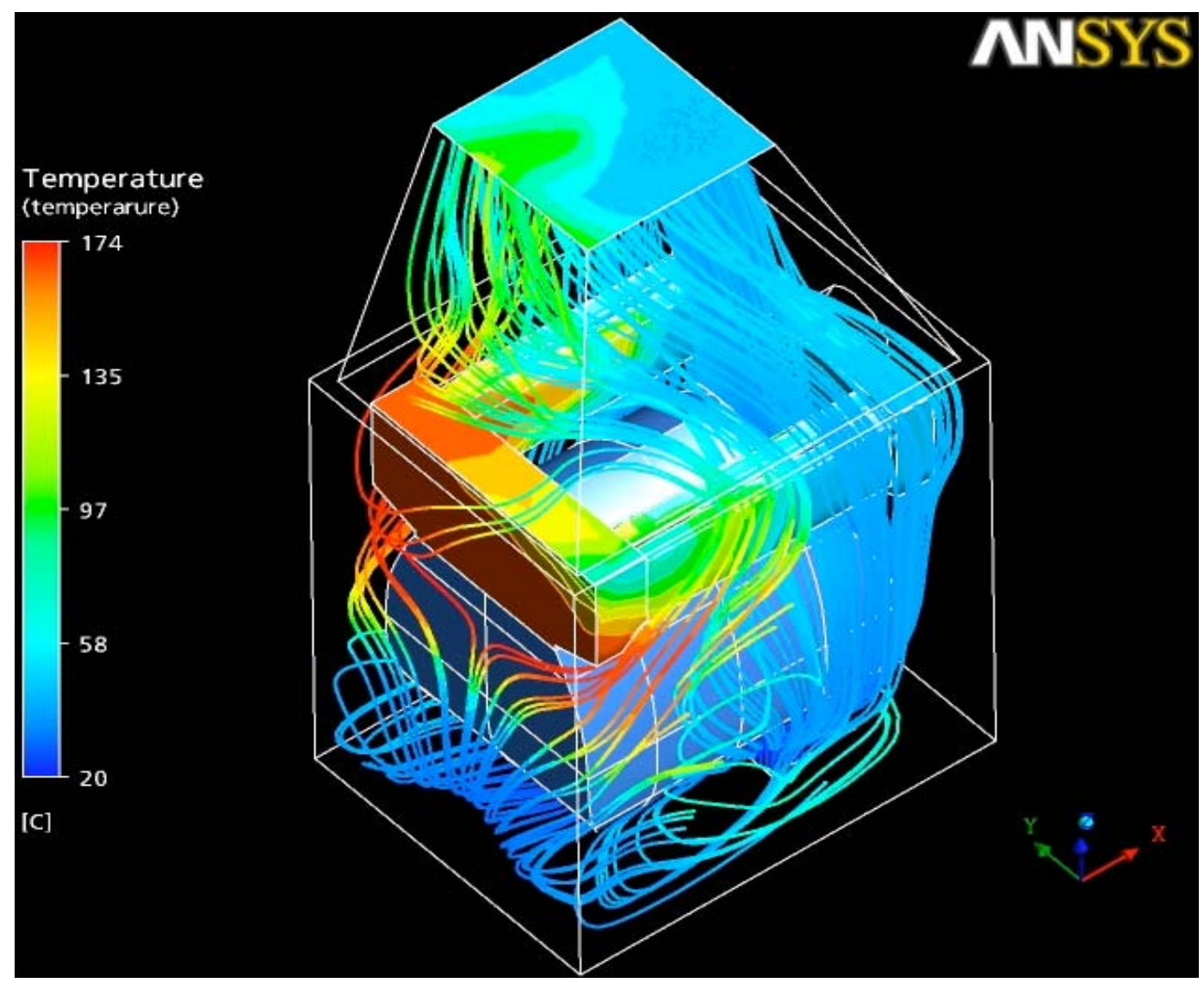

Fig. (9). Flow field and temperature distribution around the heat exchanger surfaces.

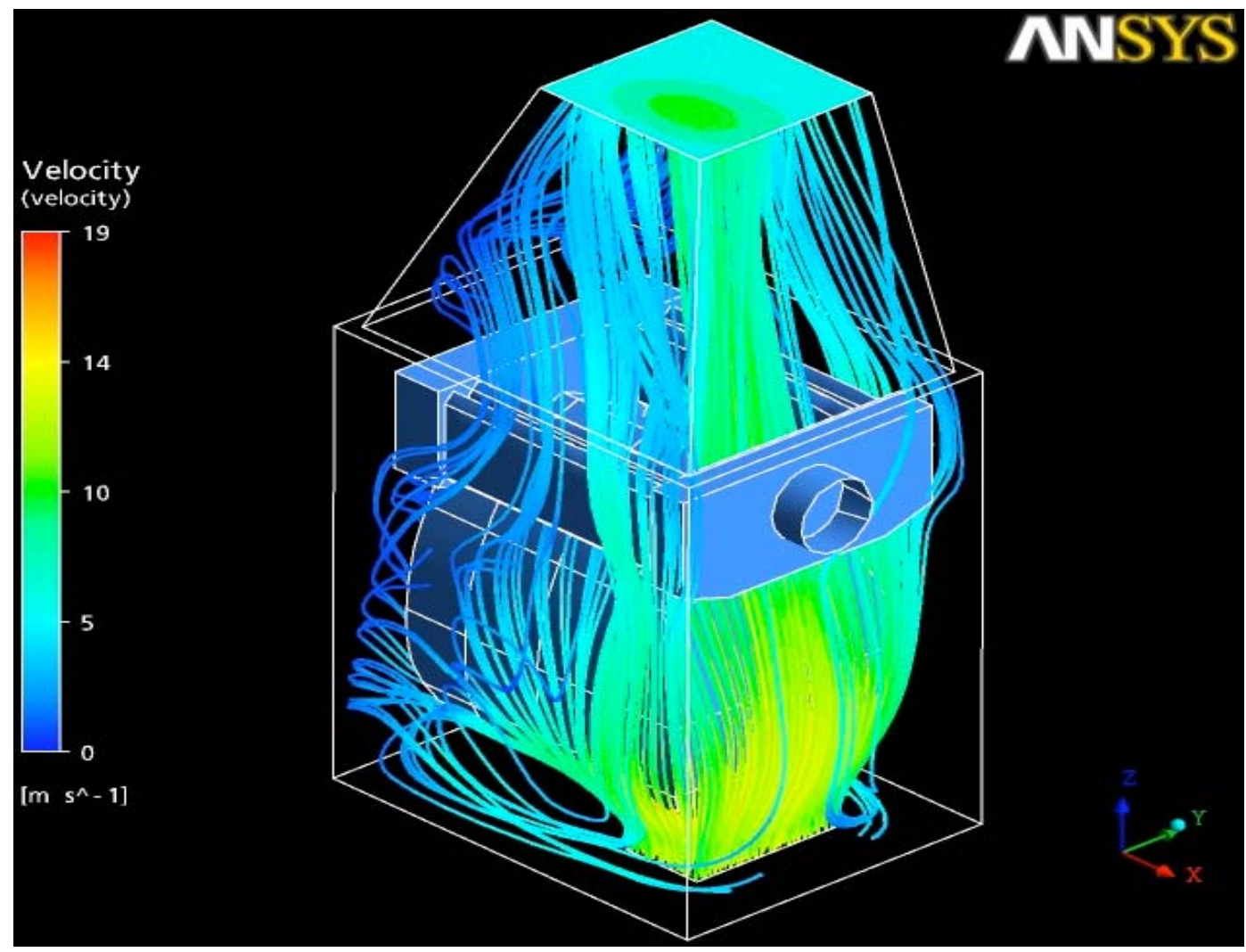

Fig. (10). Heated air velocity field between heat exchanger surfaces and covers. Streamlines become denser as we move to the right of the heat exchanger, at the exhaust gas exit side, due to the position of the fan outlet. 
made by means of conducting energy balances between inlet and outlet cross sections. To this end, the necessary files are exported by CFX Post, containing the values of air mass flow rate variation across the inlet and outlet section elements, as well as the respective values of temperatures. The energy balance result in a net thermal power gain of the heated air of the order of $28.977 \mathrm{~kW}$. This is in accordance with the measured furnace's efficiency of 0.873 .

\section{EXAMINATION OF POSSIBLE DESIGN IMPROVE- MENTS}

\section{Computational Study of the Effect of Shifting the Fan Outlet}

In this phase, we repeat the computation, assuming a small change in the geometry of the air furnace. That is, we examine the effect of shifting the position of the air inlet vent by $10 \mathrm{~cm}$ to the left, as we are looking at the furnace from the front (see Fig. (2)).

Due to the fact that we do not know in advance the air furnaces' efficiency in this new design version, we can only assume that the inlet mass flowrate remains the same as in the reference design version.

The results of the new computation are shown in Figs. (11) and (12).

The comparative optical examination of Figs. (8) and (12) (top left and right) shows significant differences at the temperature distributions at the streamlines and at the outlet planes. The files' processing showed an important expected improvement of the useful power as it appears in the top of Fig. (12) (from 28.977 to $31.537 \mathrm{k} \mathrm{W}$ ). Also the furnace's efficiency is expected to be considerably improved (from 0.869 to 0.946 ) with the proposed design modification. This is an indication that the position of inlet section to the heat exchanger volume has not been sufficiently optimized by the manufacturer. However, it is necessary to validate experimentally the expected increase of efficiency. In this context, we should keep in mind that the efficiency of modern design non-condensing light diesel fuelled furnaces, can reach $95 \%$ [25].

\section{Experimental Validation}

We have to verify the results of this new design version, so we shifted the fan by $10 \mathrm{~cm}$ to the left, as it appears in Fig. (13).

In this phase, measurements of steady state efficiency, temperature of exhaust gases, $\mathrm{A} / \mathrm{F}$ ratio and emissions were conducted at the nominal operation point of the furnace, by use of the measuring device: MRU Vario Plus Industrial [20]. The maximum efficiency attained was $88.1 \%$, for exhaust gas temperature of $245{ }^{\circ} \mathrm{C}$ and equivalence ratio $\lambda=1.25$.

Also, infrared thermography was employed in recording the temperature field at the part of the heat exchanger surface which becomes visible when the front cover is removed.

Fig. (14) shows thermograph with the measured temperature distribution with the air furnace adjusted to its optimal operation point.

Fig. (15) presents following thermograph's processing. According to this, the combustion chamber has comparted aiming at the better modeling of heat transfer.

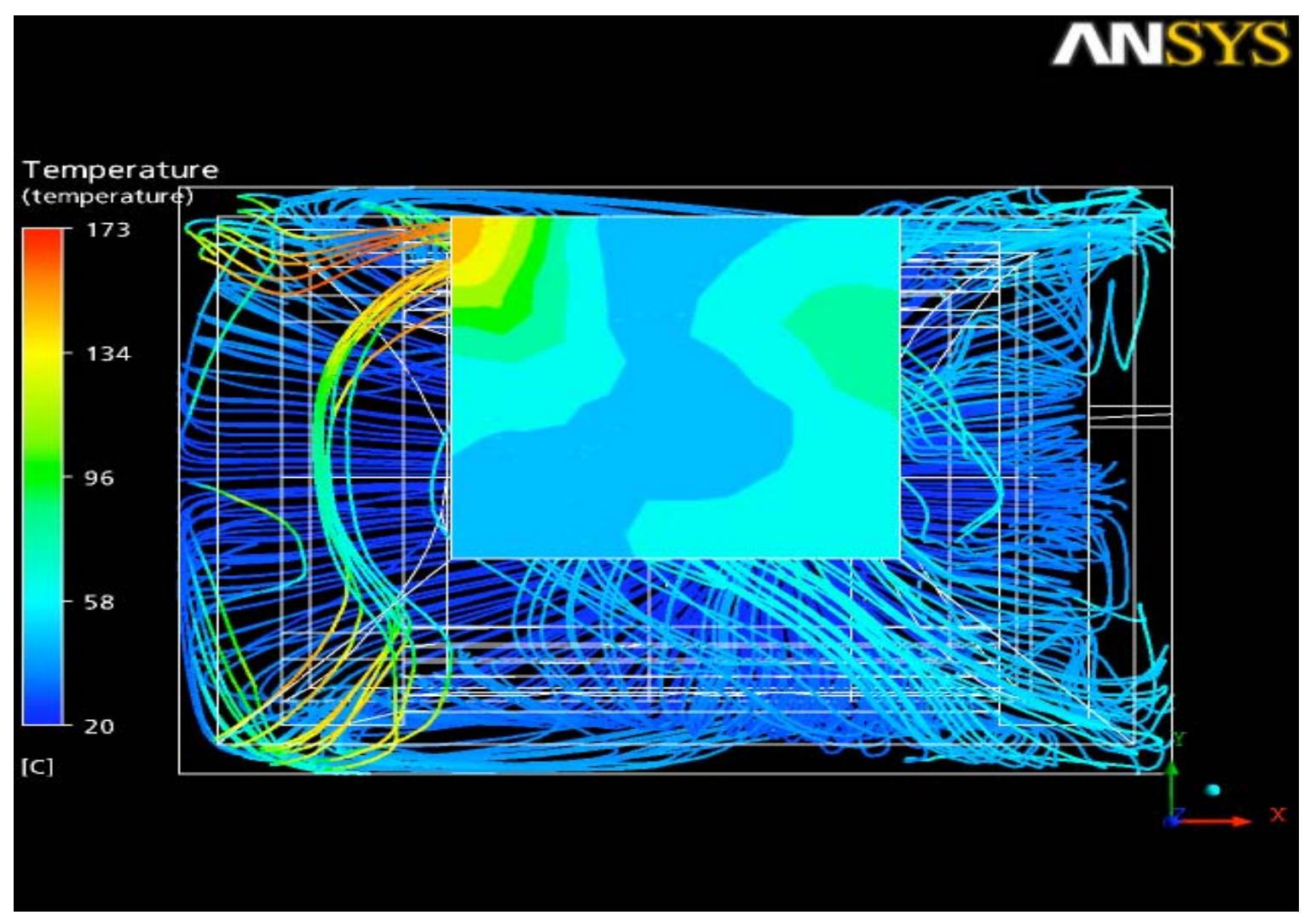

Fig. (11). Temperature distribution at the exit of the control volume under study. 

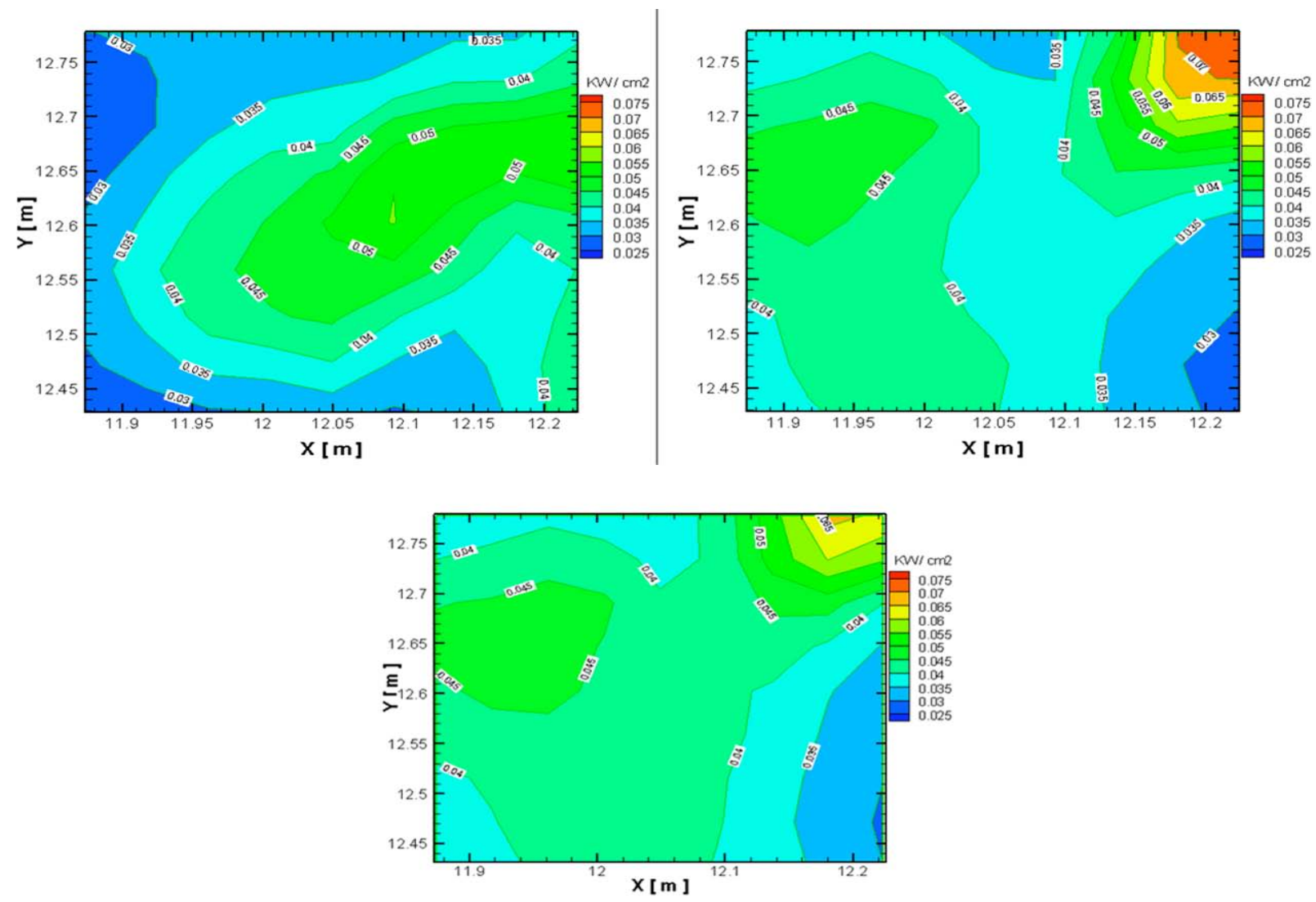

Fig. (12). Comparison of enthalpy flow fields at the outlet cross section. Reference case (left) versus the shifted inlet case, based on the assumption that the heat exchanger surface temperature field is not affected (right). At the bottom, the result of the computation of the improved- shifted inlet case, based on the real heat exchange surface temperature field, as measured by infrared thermography.

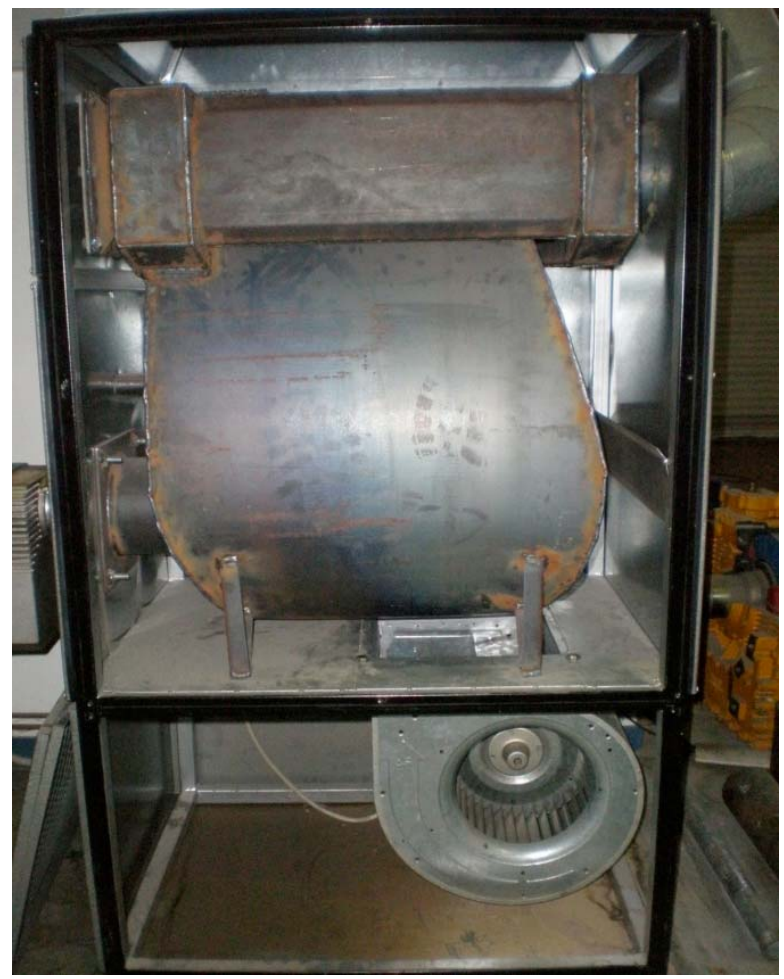

Fig. (13). Exposed heat exchanger surfaces of the $30,000 \mathrm{kcal} / \mathrm{h}$ air furnace after the new position of the fan and the removal the front cover and the fan inlet grid.

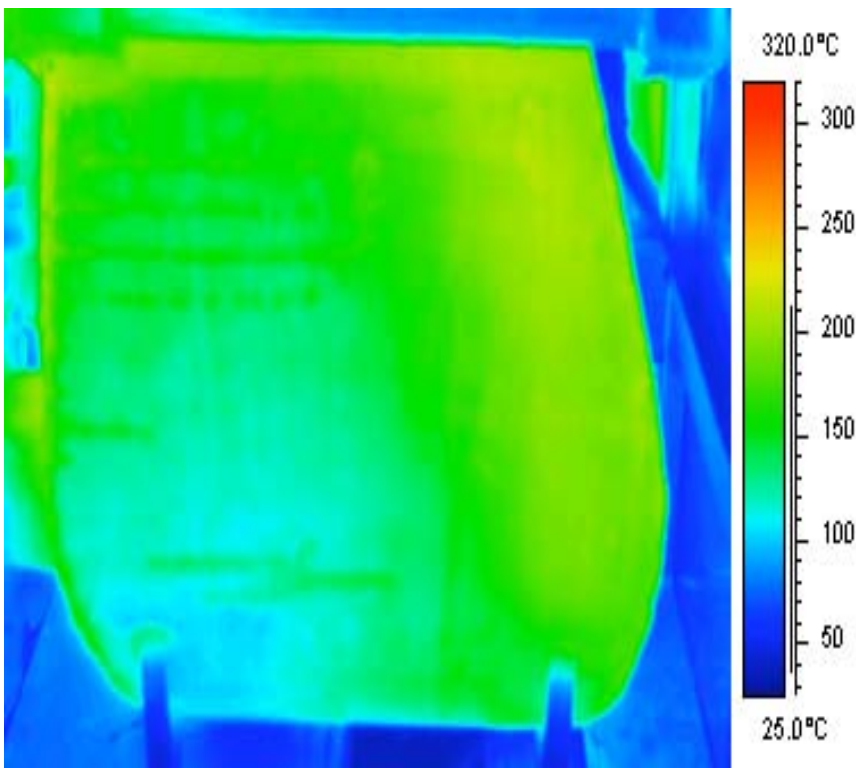

Fig. (14). Temperature distribution at the heat exchanger surfaces at the optimal operation point, resulting from the analysis of the related thermograph.

Characteristic figures from the control volume and the computational grid are presented as follows:

Fig. (16) shows solid model of the air furnace and the control volume. 


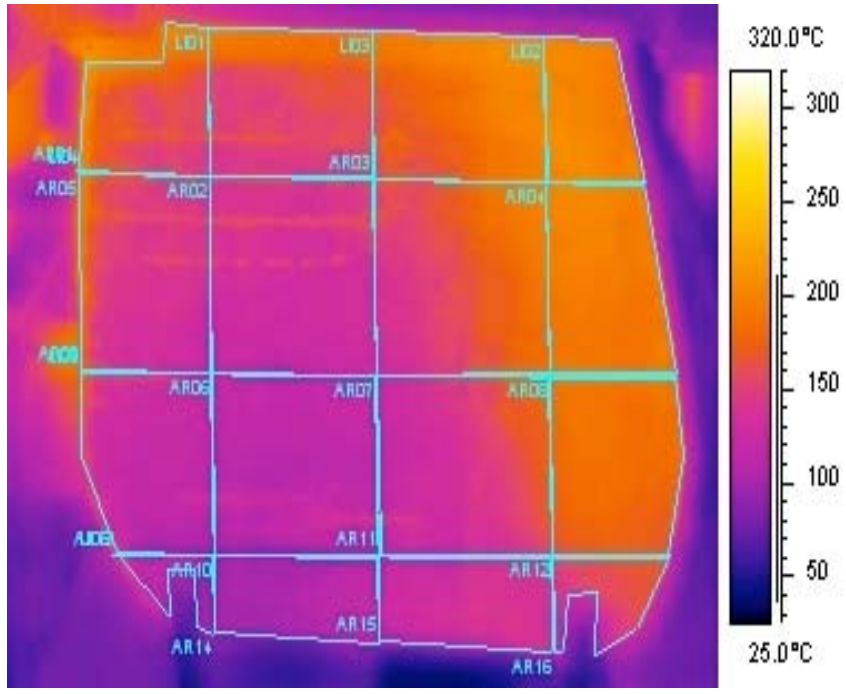

Fig. (15). Regions of combustion chamber.

Fig. (17). presents computational grid for the control volume.

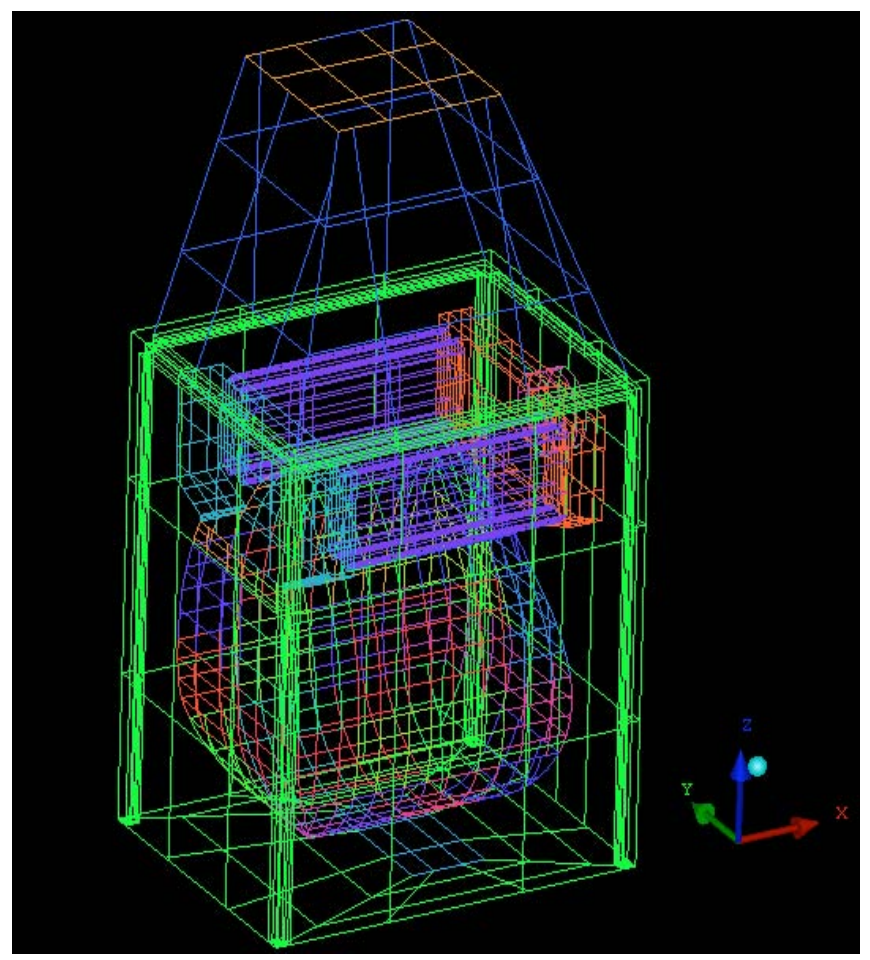

Fig. (16). Solid model of the air furnace and the control volume.

\section{Determination of Boundary Conditions}

The boundary conditions for the improved design version are set following the methodology of the reference case, with the necessary modification of the wall temperatures (according to the new thermographs - see Fig. (15)). In addition, it was necessary to correct the air mass flowrate.

The reason for this modification is that the processing of enthalpy balances (see Fig. 12) indicated incompatible values between computed and measured furnace efficiency.

For this reason, the possibility of increased air flowrate was investigated. According to the fan manufacturer's data higher flowrates, reaching $1 \mathrm{~kg} / \mathrm{s}$ could be attained if the pressure losses in the heat exchanger are reduced with the new design version both in the inlet and outlet section. Indeed, an examination of the geometry in the new design version supports this assumption. Testing of this assumption was carried out based on enthalpy balances with the new computational results and the measured efficiency results.

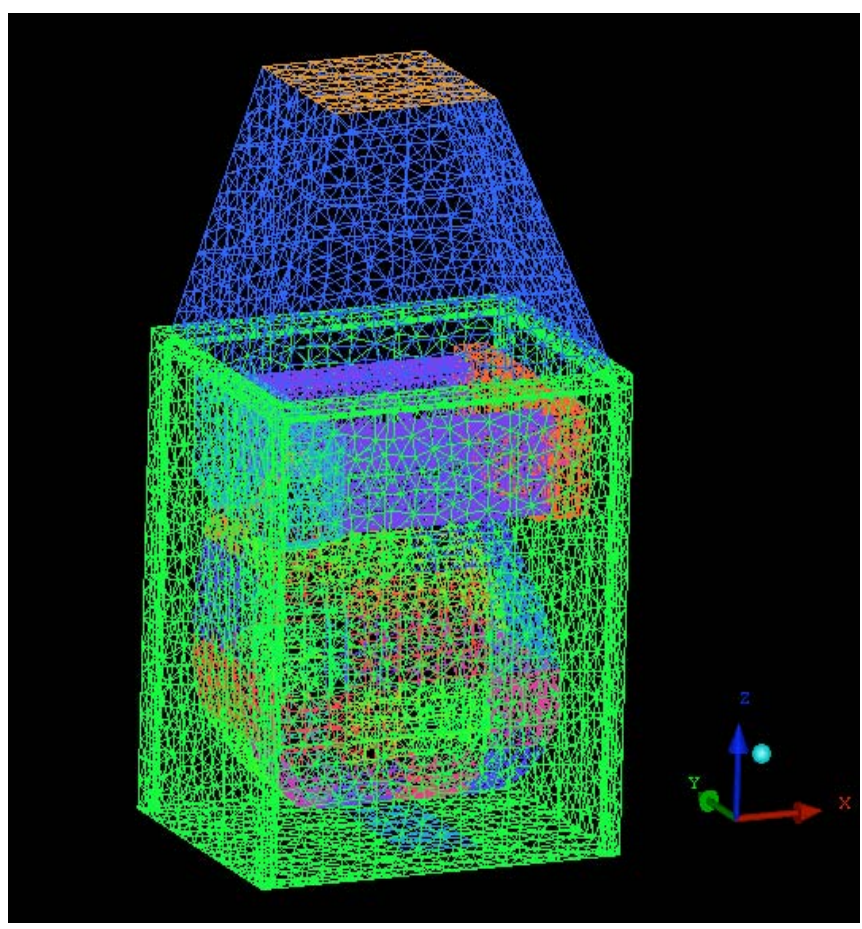

Fig. (17). Computational grid for the control volume.

\section{Presentation of Results}

The visualization - presentation of results is carried out in this phase, in the form of streamlines and temperature and velocity contours across planes by use of the CFX Post software. Examples of the results are presented in the figures below.

Fig. (18) shows the temperature field at the exit of the plenum, with the improved design, based on the experimentally determined heat exchanger surface temperature field.

Fig. (19) presents typical streamlines and temperatures of the air flowing around the heat exchanger surfaces. The improvement is apparent in the more homogeneous streamline density.

Fig. (20) shows the velocity field between the heat exchanger surface and the covers, which results in better exploitation of the heat exchanger.

Finally, Fig. (12) presents the comparison of the enthalpy flow fields at the outlet cross section. If we compare the estimated improvement of the enthalpy field at top right with the experimentally verified enthalpy field at the bottom of this figure, we conclude that the field becomes more homogenized, however, the overall enthalpy increase of the heated air is not as high as originally estimated.

\section{Discussion of Results}

According to the results shown in the above figures, it can be concluded that the temperature and enthalpy flow 


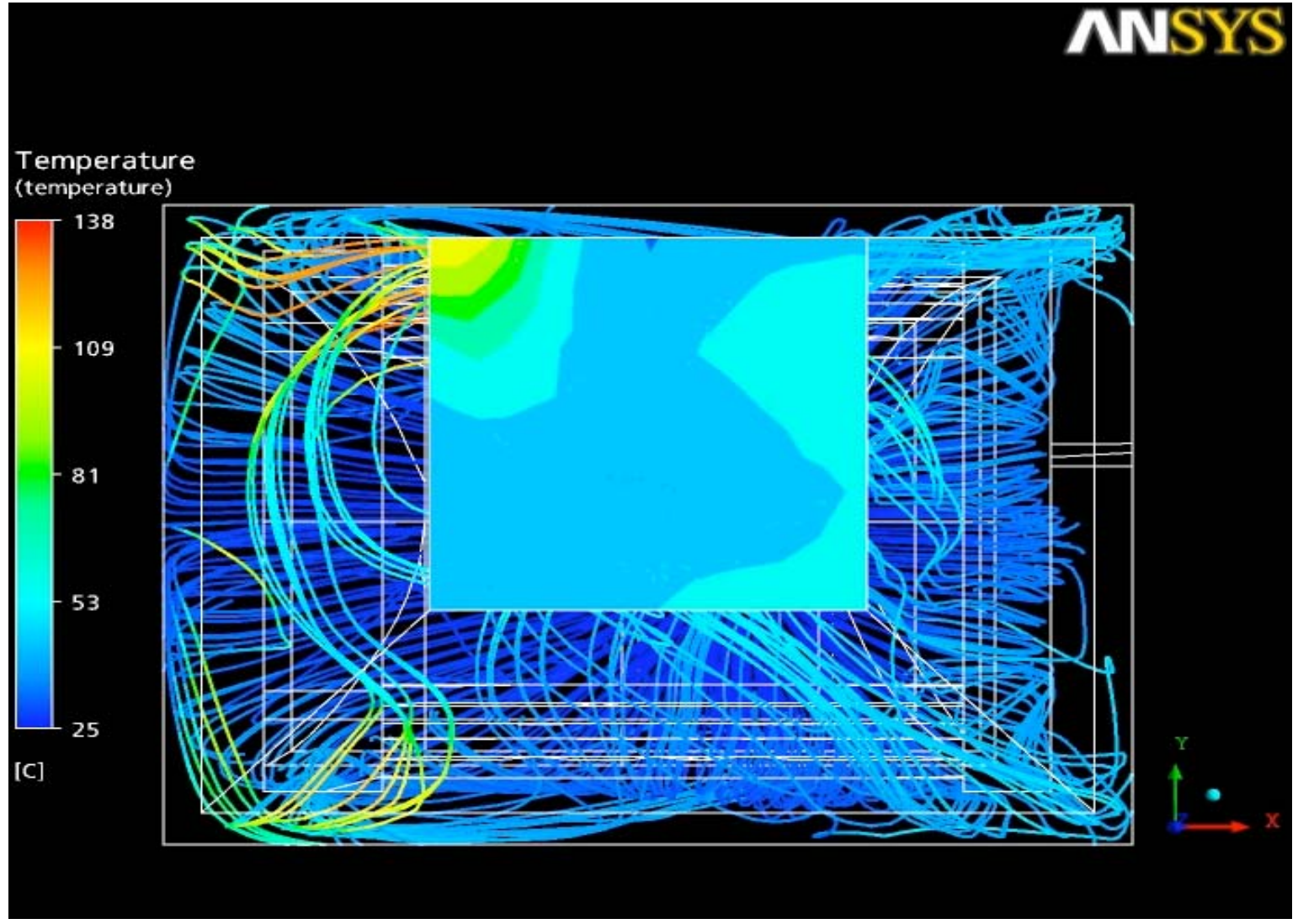

Fig. (18). Computed temperature field at the exit of plenum and at the streamlines inside the control volume.

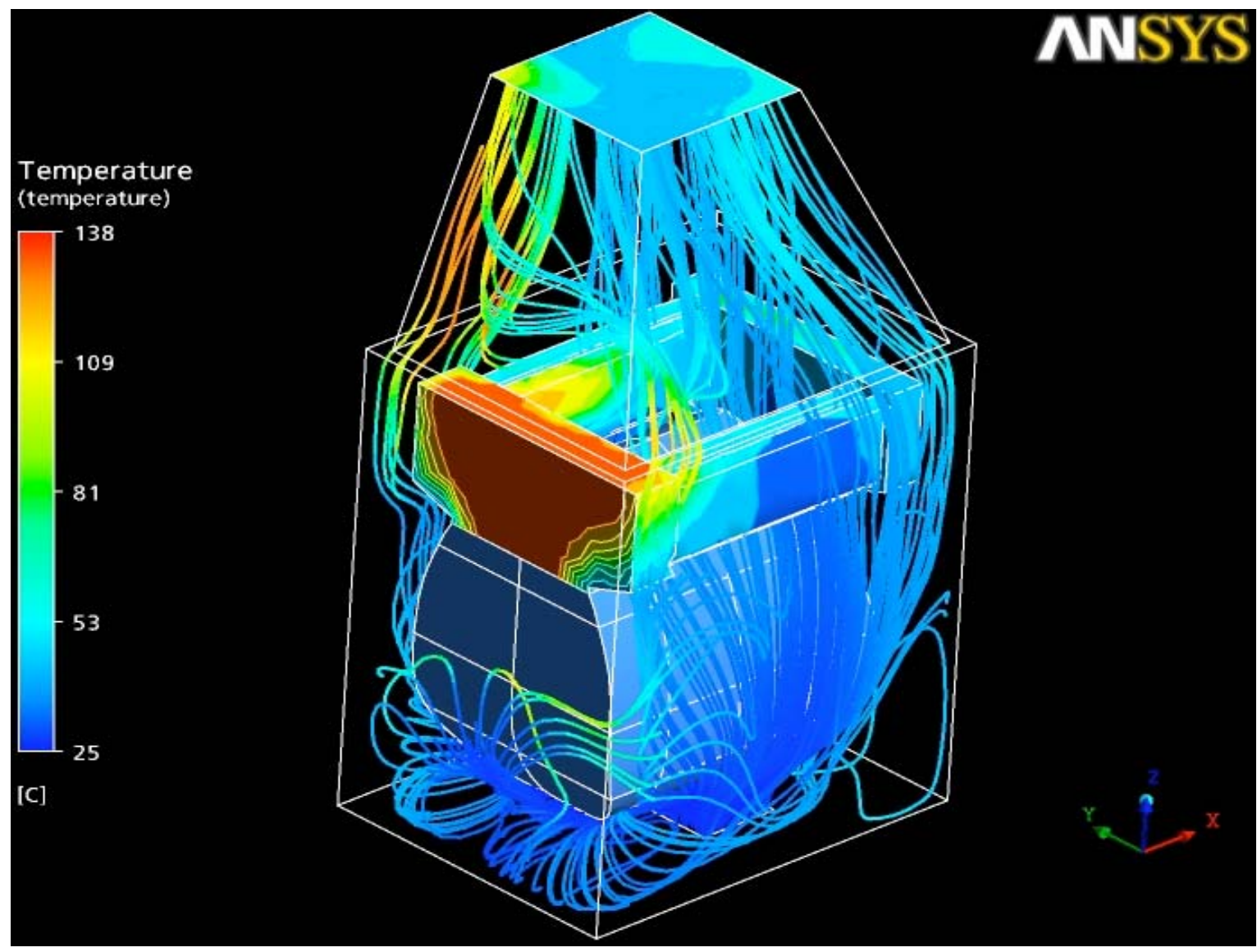

Fig. (19). Flow field and temperature distribution around the heat exchanger surfaces: improved design. 


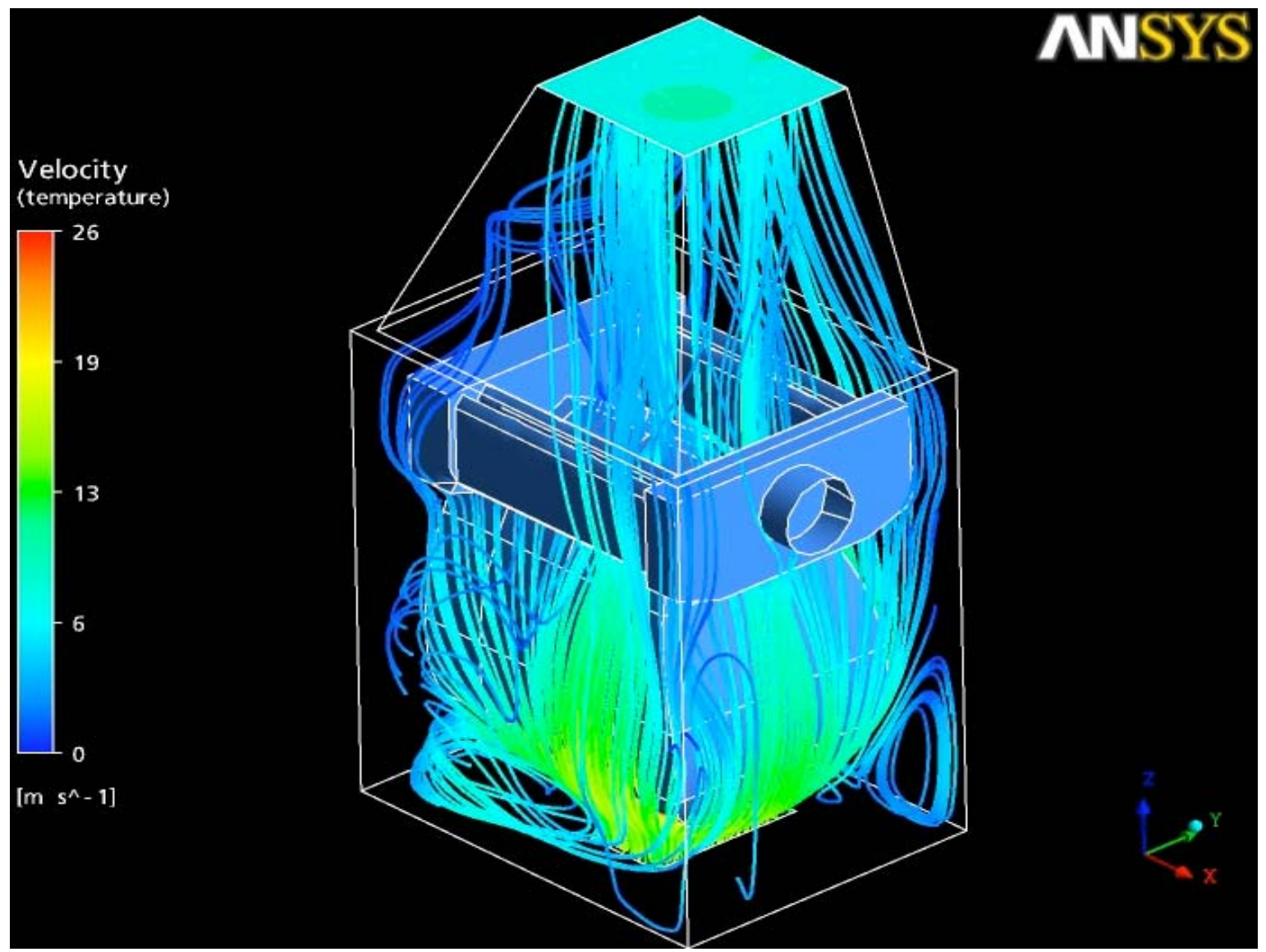

Fig. (20). Air velocity field between heat exchanger surfaces and covers with the improved design. The improvements in the better homogenization of the streamline density is apparent.

distribution at the outlet cross section has now become more homogeneous (see Figs. (12) and (18)). The large temperature gradients that were apparent in the results of the original design (see Figs. (8) and (11) are now relaxed. The results from the processing of the output files by means of energy balances, indicate an improvement of the useful power transferred to the heated air, from 28.977 to $29.562 \mathrm{~kW}$. The measured furnace's efficiency is improved accordingly (from 0.869 to 0.89 ), with the proposed design modification. In the reference case, the streamlines were seen to come in good thermal contact only with a limited part of the heat exchange surfaces. In the improved design, on the other hand, the combustion chamber and the heat exchanger are flown around in a more homogeneous way by the streamlines. This explains the measured efficiency improvements.

\section{CONCLUSIONS}

- The combination of a commercial CFD code with the technique of infrared thermography was successfully demonstrated in the study of the 3D flow field and heat transfer in the heat exchanger surface of an air furnace.

- Infrared thermography was employed in the determination of temperature boundary conditions in the heat exchanger surfaces that interact thermally with the heated air.
- The 3D flow and heat transfer in the control volume of the air furnace was computed by CFD at steady state, at its nominal operation point.

- The flow field is visualized by means of 3D streamlines and velocity and temperature fields at characteristic cross sections. Additional checks are made by means of a hot wire probe.

- The numerical results were checked by means of energy balances in the inlet and outlet sections of the control volume enclosing the heated air stream. In this way, the air furnace efficiency can be computationally predicted.

- $\quad$ Computed efficiency improvement from the baseline $86.9 \%$ to $89 \%$ was predicted by a modified positioning of the inlet section from the air supply fan to the main control volume that was suggested by the study of the flow field.

- $\quad$ By means of the measurements the exhaust gas temperature was reduced about $16{ }^{\circ} \mathrm{C}$ (from $261{ }^{\circ} \mathrm{C}$ to 245 ${ }^{\circ} \mathrm{C}$ ) and the furnace's efficiency was improved (from $87.3 \%$ to $88.1 \%$ ).

- The methodology developed looks promising in the support of design improvements in air furnaces of this type. 


\section{ACKNOWLEDGEMENTS}

Special thanks are due to Professor Herricos Stapountzis for the supply of the ANSYS CFX license, his helpful discussions and support in the experimental layout and the interpretation of computational results. Also, special thanks are due to our former collaborators, Dr. George Pontikakis - now at company EXTHERM, Thessaloniki, Greece - for the supply of the air furnace prototype and the detailed design drawings, as well as helpful discussions and suggestions, as well as Dipl.-Ing, Loucas Demetriades for his precious contribution in the experimental part of this work.

\section{NOMENCLATURE}

$$
\begin{array}{ll}
\mathrm{A} / \mathrm{F} & =\text { Air-to-fuel ration } \\
\lambda & =\text { Equivalence ratio } \\
\mathrm{T} & =\text { Temperature }\left[{ }^{\circ} \mathrm{C}\right] \\
\dot{\mathrm{m}} & =\text { Mass flowrate }[\mathrm{kg} / \mathrm{s}] \\
\mathrm{P} & =\text { Gauge pressure }[\mathrm{Pa}] \\
\mathrm{U} & =\text { heat transfer coefficient }\left[\mathrm{W} / \mathrm{m}^{2} \mathrm{~K}\right]
\end{array}
$$

\section{REFERENCES}

[1] Recknagel; Sprenger, Heizung + Klimatechnik. R. Oldenbourg Verlag: 1995.

[2] Kerch, R. Hot air furnace, US Patent 1978 4215669. August 5, 1978.

[3] Tallman, W. R.; McDevitt, S. C.; Delancey, W. H. Gas-fired condensing mode furnace, US Patent 1985 4515145, 1985.

[4] Hugghins, G. J.; Holmes, L. W. Multistage warm air furnace with single stage thermostat and return air sensor and method of operating same, US Patent 2005 6925999, 2005.

[5] Schonberger, M. L. Hot air furnace, US Patent 20056923173 , 2005.

[6] Kujawa, M.; Waterman, T. J. Air intake for furnace, US Patent $19945313930,1994$.
[7] Asotani, T.; Yamashita, T.; Tominaga, H.; Uesugi, Y.; Itaya, Y.; Mori, S. Prediction of ignition behavior in a tangentially fired pulverized coal boiler using CFD. Fuel, 2008, 87(4-5), 482-490.

[8] Diez, L. I.; Cortes, C.; Pallares, J. Numerical investigation of NOx emissions from a tangentially-fired utility boiler under conventional and overfire air operation. Fuel, 2008, 87(7), 1259-1269.

[9] Gomez, A.; Fueyo, N.; Diez, L.I. Modelling and simulation of fluid flow and heat transfer in the convective zone of a power-generation boiler. Appl. Therm. Eng., 2008, 28(5-6), 532-546.

[10] He, B.; Zhu, L.; Wang, J.; Liu, S.; Liu, B.; Cui, Y.; Wang, L.; Wei, G. Computational fluid dynamics based retrofits to reheater panel overheating of No. 3 boiler of Dagang Power Plant. Comput. Fluid, 2007, 36(2), 435-444.

[11] Pallares, J.; Arauzo, I.; Williams, A. Integration of CFD codes and advanced combustion models for quantitative burnout determination. Fuel, 2007, 86(15), 2283-2290.

[12] DIN 4702 Teil 1: Heizkessel: Begriffe, heiztechnische Anforderungen, Pruefung, Kennzeichnung. In DIN, Ed. 1990.

[13] ASME Boiler and Pressure Vessel Code, Section IV: Heating Boilers In 2004.

[14] CAN/CSA B140.4-04 Oil-Fired Warm Air Furnaces, Includes Updates No. 1 and No. 2 In 2007, Canadian Standards Association

[15] DIN EN 303-1, DIN EN 303-2: Heating boilers with forced draught burners - Part 1: Terminology, general requirements, testing and marking, Part 2: Special requirements for boilers with atomizing oil burners. In 1998 (includes amendment A1: 2003)

[16] Pontikakis, G. EXTHERM: Thessaloniki 2006.

[17] ANSYS ANSYS CFX Computational Fluid Dynamics software. http://www.ansys.com/products/cfx.asp (30.1.2008).

[18] PTC ProEngineer Wildfire 3D CAD software. http://www.ptc.com/ (30.1.2008).

[19] Tecnifan Direct Drive Centrifugal Fans characteristics. http://www.tecnifan.es/ (30.1.2008).

[20] MRU MRU Vario Plus Industrial semi-continuous multi-gas analyzer. http://www.mru.de/ (30.1.2008).

[21] Tziourtzioumis, D. Flow and heat transfer modeling in a low-end air furnace assisted by infrared thermography; LTTE, University of Thessaly: Volos 2008.

[22] Flir, ThermaCam Researcher Professional 2.8 SR-3. 2007.

[23] TSI Velocicalc Air Velocity Meters. www.tsi.com (30.1.2008).

[24] NI Labview graphical development of scalable test, measurement, and control applications. http://www.ni.com/ (30.1.2008).

[25] Goodman GMV95 Gas Furnace: 95\% AFUE, Multi-Position, TwoStage, Variable-Speed http://www.goodmanmfg.com/Home/Produc ts/tabid/53/Default.aspx (30.1.2008). 